\title{
METÁFORAS SOBRE EMOÇÕES: UMA CENA COGNITIVA DE TEATRO E DE FORÇA
}

\author{
METAPHORS ABOUT EMOTIONS: A COGNITIVE FRAMEWORK OF STAGE AND \\ FORCE.
}

Heronides Moura

Universidade Federal de Santa Catarina (UFSC)

Maiara Knihs

Mestranda do Programa de Pós-graduação em Literatura (UFSC)

\section{Resumo}

Neste artigo, descrevemos metáforas sobre emoções, que são conceptualizadas de acordo com diferentes categorias ontológicas. Apesar dessas diferenças ontológicas, as metáforas estudadas apresentam muitas similaridades conceptuais. A hipótese adotada é que tais estruturas conceptuais derivam da transitividade, ou seja, construções com sujeito e objeto direto. As metáforas estudadas herdam esquemas associados à transitividade, através dos seguintes modelos cognitivos: modelo teatral, modelo da bola de bilhar e modelo da dinâmica de forças.

Palavras-chave: metáfora, emoção, transitividade, ação, dinâmica de forças, modelo cognitivo.

\begin{abstract}
In this paper, metaphors about emotions are described. These emotions are conceptualized according to different ontological categories. Notwithstanding these ontological differences, the metaphors described show many conceptual similarities. The hypothesis put forward is that such conceptual structures are derived from transitivity, i.e., constructions with subject and direct object. The metaphors described inherit frames connected to transitivity, through the following cognitive models: stagemodel, billiard-ball model and force dynamics model.
\end{abstract}

Key words: metaphor, emotion, transitivity, action, force dynamics, cognitive model.

\section{INTRODUÇÃ̃o}

Neste artigo, buscamos analisar diferentes conceptualizações de emoções humanas, através da análise de enunciados metafóricos. Para isso, coletamos na web metáforas em que sensações como medo, paixão, amor, saudade, sentimento, esperança, ódio e mágoa foram conceptualizadas como ser consciente, objeto, ser vivo, artefato e doença. Segundo Lakoff e Johnson (2002), essas metáforas, denomindas de ontológicas, são o mecanismo cognitivo que nos permite pensar e conceber os sentimentos, e em última instância, são as metáforas que influenciam na maneira como sentimos (cf. MOURA, 2005). A nossa hipótese, a partir da análise de dados, é que, para além dessas categorizações ontológicas, há características comuns a todas essas diferentes metáforas. Essas características comuns derivam do fato de que, nas sentenças 
analisadas, a relação experienciador-emoção é codificada em termos de modelos cognitivos da ação.

Para explicitar essas características, vamos utilizar os seguintes modelos cognitivos da ação verbal: o modelo da bola de bilhar, o modelo teatral e o modelo da dinâmica de forças (LANGACKER, 2002; TALMY, 2003). A nossa proposta é que esses modelos cognitivos da ação verbal estruturam os enunciados metafóricos sobre emoções que analisamos. Como a estrutura da ação é a mesma em todos os casos analisados, as diferenciações ontológicas não alteram as características básicas identificadas. Assim, propomos uma combinação de modelos ontológicos e modelos de ação como base conceptual para a interpretação das metáforas analisadas. As diferentes ontologias são responsáveis pelas diferenças conceptuais entre as metáforas analisadas; a estrutura da ação verbal, representada pelos modelos cognitivos citados, é responsável pela semelhança conceptual entre as metáforas analisadas.

\section{MODELOS COGNITIVOS DA AÇÃO}

A estrutura conceptual que está por trás das metáforas parece estar diretamente ligada a modelos cognitivos que organizam nosso mundo mental. Quando nos referimos a um modelo cognitivo, pressupomos regularidades significativas nas expressões linguísticas associadas a eles. Nas metáforas analisadas, destaca-se como um traço comum a externalização da emoção em relação ao experienciador. São exemplos disso as metáforas:

1 (a) Afugentei a paixão http://www.magdaalmodovar.com/instinto_de conservacao.htm

(b) Destrui nosso amor http://www.letras.com.br/avioes-do-forro/cansei-de-esperar

(c) Tive de sufocar o medo. http://www.centraonline.com.br/Literalidades/Autestesia/ColchaDeClich $\underline{\text { es.html }}$

(d) Neste momento, independente da resposta, você irá ter a possibilidade de começar a desmontar o medo que está o paralisando. http://360graus.terra.com.br/montanhismo/default.asp?did=13283\&actio $\underline{\mathrm{n}=\text { coluna }}$

(e) O processo de extirpar o medo de nossa vida terrena começa pelo nosso centramento através da meditação.(23/10/2008) http://www.portalangels.com/licoes_de vida81.htm

As emoções metaforizadas acima são conceptualizadas como algo que pode estar fora do experienciador e que tem existência independente. Esse fenômeno já havia sido considerado por Reddy (1993), quando afirmou que existem três categorias fundamentais que constituem um dos arcabouços da metáfora do conduto: 1) na fala ou na escrita, pensamentos e sentimentos são deslocados para um "espaço ideacional" externo; 2) pensamentos e sentimentos são reificados nesse espaço externo, de modo que existem independentemente de qualquer necessidade de seres humanos que os pensem ou os sintam; 3) esses pensamentos ou sentimentos podem encontrar, ou não, o 
seu caminho de volta para a cabeça dos seres humanos. Esse terceiro item não é relevante para o nosso trabalho, pois Reddy teorizou sobre as metáforas no campo da comunicação, diferentemente do nosso corpus, que está restrito ao campo da sensação.

Essa reificação da emoção varia de acordo com a seleção verbal. Ou seja, o tipo de existência atribuída ao sentimento depende da classe verbal ao qual ele está ligado. No exemplo 1(a), o verbo afugentar transfere o conceito de um ser consciente ou perceptivo ao sentimento "paixão"; em 1(b), o verbo destruir sugere que o "amor" pertence à classe dos objetos; em 1(c), o verbo sufocar indica que o "medo" é concebido como um ser vivo; em 1(d), o verbo desmontar sugere que o sentimento é interpretado como um artefato; em 1(e), o verbo extirpar indica que o sentimento é conceptualizado como uma doença.

Em suma, há um elemento comum a todos os enunciados metafóricos citados em (1): todos eles reificam as sensações humanas, como entidades externas ao experienciador. Por outro lado, o conteúdo semântico específico de cada verbo, nos exemplos citados, estabelece categorias ontológicas específicas: ser consciente, objeto, ser vivo, artefato e doença, respectivamente.

Para explicar como funciona essa reificação dos sentimentos, vamos nos utilizar dos modelos cognitivos propostos para descrever a relação entre seres e/ou objetos, tais como representados em sentenças transitivas (note que as sentenças em (1) apresentam verbos transitivos diretos).

Na linguística cognitiva, há três modelos (modelo teatral, modelo da bola de bilhar e modelo da dinâmica de forças) que tentam explicitar as relações transitivas entre entidades, correspondendo a modelos cognitivos da ação verbal. Esses modelos são complementares e vão servir de base para nossa análise.

Langacker (2002, p. 209) propõe modelos cognitivos que servem para descrever o esquema cognitivo prototípico associado a uma oração transitiva finita. $\mathrm{O}$ autor descreve dois modelos: o modelo teatral ${ }^{1}$ e o modelo da bola de bilhar ${ }^{2}$, que são empregados para apresentar a noção de agente e paciente, no primeiro, e de transmissão de energia por meio de contato físico, no segundo.

O modelo da bola de bilhar prevê um mundo em que objetos ocupam lugares distintos. Dentre os objetos, existem aqueles que são capazes de se mover por meio de uma energia própria e aqueles que são capazes de receber energia a partir de uma fonte externa. Essa transferência se dá pelo contato físico entres os objetos, e pela transmissão de energia entre eles. Os objetos que são autossustentáveis como fonte de energia são identificados ao conceito de agente e os que necessitam de uma fonte externa são associados ao conceito de paciente.

Incorporando essas noções, podemos definir o modelo teatral como um modelo composto por um cenário onde contracenam o agente e o paciente. O papel de agente é concebido como uma fonte de energia voluntária, ou seja, corresponde à entidade que age voluntariamente e que tem potencial de transmitir energia a algum objeto externo. $\mathrm{O}$ paciente, por sua vez, é inanimado e absorve a energia transmitida por um contato físico, sofrendo com isso uma mudança de estado. Para Langacker (2002), esses seriam 
os dois participantes que contracenam em uma ação ou evento prototípico. Entretanto, pode haver entre o agente e paciente um instrumento que funciona como um meio transmissor de energia:

\section{AGENTE-->(INSTRUMENTO)--> PACIENTE}

$\mathrm{O}$ agente, como mostra o diagrama, está em uma ponta extrema da cadeia de energia, e na outra ponta se situa o paciente. Langacker (2002) denomina essas posições como cabeça e coda. Além disso, há na cena um observador que observa o evento de um ponto externo e privilegiado. $\mathrm{O}$ evento é, portanto, assim representado (A corresponde ao agente, $\mathrm{B}$ ao paciente e $\mathrm{O}$ ao observador):

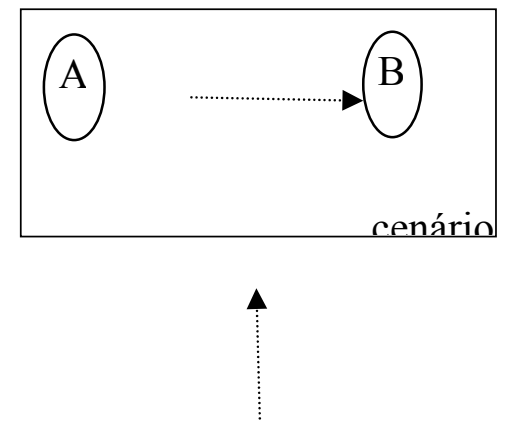

(O)

Os modelos teatral e da bola de bilhar são compatíveis com um terceiro modelo, o da dinâmica de forças, proposto por Talmy (2003). De acordo com este modelo, na cena verbal prototípica que corresponde à oração transitiva, há uma interação entre dois participantes. O primeiro participante da cena a ser descrita sofre a ação exercida pelo segundo participante, o que resulta num estado específico do primeiro participante. Este primeiro participante é chamado de agonista, e corresponde ao foco da cena. O agonista exerce também uma força, que pode ou não ser sobreposta pela força do antagonista. $\mathrm{O}$ agonista possui uma tendência natural para o repouso ou para o movimento. $O$ antagonista é o que causa mudanças nesse estado original do agonista. A dinâmica de forças está assim diretamente associada à noção de causa. Pinker (2007, p. 217) afirma que percebemos a causatividade em termos de forças e não apenas em termos de correlações entre fatos. Se algo aconteceu, isso se deve ao fato de que um dos participantes da cena tinha uma força intrínseca que provocou o acontecimento. Uma diferença entre o modelo da bola de bilhar e o modelo da dinâmica de forças é que neste último o agonista (que corresponde ao paciente) é também dotado de uma força. Há sempre uma interação de forças neste modelo, não havendo participantes inteiramente passivos.

Assim como Langacker (2002) e Talmy (2003), outros autores, de linhas teóricas distintas, também abordaram a interação entre a estrutura conceptual dos eventos "reais" e a estrutura linguística que serve para representá-los. Ackerman e Moore (2001), por exemplo, retomam as considerações de Dowty $(1989 ; 1991)$ sobre os papéis temáticos, isto é, os papéis que se definem pela relação semântica entre predicadores e argumentos, tais como agente, paciente, experienciador, etc. Dowty (1989) propôs que 
os papéis temáticos fossem tratados como categorias prototípicas. Essas categorias são inteiramente convergentes com o modelo representacional de Langacker (2002), exposto acima. Observe o quadro a seguir, baseado em Dowty (1989) e Ackerman e Moore (2001):

QUADRO 1. Papéis temáticos como categorias prototípicas

\begin{tabular}{l|l}
\hline Propriedades do agente prototípico & Propriedades do paciente prototípico \\
\hline $\begin{array}{l}\text { - tem um envolvimento volitivo no } \\
\text { evento (ou um estado de } \\
\text { consciência/percepção) }\end{array}$ & - sofre uma mudança de estado \\
\hline $\begin{array}{l}\text { - causa o evento ou a mudança de } \\
\text { estado }\end{array}$ & - é afetado pela causa \\
\hline $\begin{array}{l}\text { - movimenta-se em relação à posição de } \\
\text { outro participante }\end{array}$ & - é um participante estático \\
\hline - existe independentemente do evento & $\begin{array}{l}\text { - não existe (completamente) } \\
\text { independente do evento }\end{array}$ \\
\hline
\end{tabular}

Esses traços são compatíveis com as características dos modelos cognitivos propostos por Langacker (2002). Além disso, nos dados que analisamos, o agente também pode ser associado ao sujeito gramatical e o paciente ao objeto direto, que sempre será, nos nossos dados, um sentimento. Vejamos alguns exemplos:

2 (a) voce disse que não sabia ou nao tinha nada a dizer, e disse tudo, montou remontou, desmontou o amor, quero não quero, quero de novo, como será, porque será, será?

http://pensamentosefotos.blogspot.com/2008/07/lua.html

(b) Ele cortou o medo que tinha de não superar seus limites. http://www.fanfiction.net/s/4367698/1/A tranq_ilidade_que_aperfei_oa a espada

(c) Quero rever em meus pensamentos a sua imagem e destruir a saudade que na minha vida quer por fim http://www.poemas-de-amor.net/blogues/nikko/silencio_sem_eco

Em 2(a), (b) e (c), o sujeito da oração, que podemos convencionar chamar de participante 1, o qual corresponderia ao agente do modelo teatral e à entidade fonte de energia do modelo da bola de bilhar, age/movimenta-se voluntariamente e transfere sua energia para um participante 2, inanimado, que ao receber essa energia muda de estado. O participante 2 é, portanto, o paciente - aquele que sofre a ação. Observemos que o processo cognitivo da construção metafórica, no que diz respeito a esses casos, é muito similar ao processo não-metafórico de ação verbal transitiva. A diferença fundamental é que os verbos desmontar, cortar e destruir, ao serem utilizados metaforicamente, descartam o contato físico entre agente e paciente, isto é, há uma transferência de energia metaforizada que resulta, respectivamente, na desmontagem, no corte e na destruição do sentimento. 
Langacker (2002) já havia apontado, nas orações transitivas finitas, a possibilidade de extensões do domínio literal, com a representação de uma cadeia de energia metafórica:

Embora a energia física não precise estar envolvida, o sujeito em cada caso provoca o movimento do objeto, e pode assim ser representado como uma fonte de energia abstrata. (LANGACKER, 2002, p.221) ${ }^{1}$

Vejamos alguns exemplos de Langacker (2002) para casos de transmissão de energia abstrata, mesmo em domínio literal:

3 (a) I gave that information to all the neighbors. (Eu dei aquela informação para todos os vizinhos)

(b) The bank transferred the deed to the new owners. (O banco transferiu a escritura para os novos proprietários)

(c) He told those lies to anybody who would listen. (Ele disse aquelas mentiras para qualquer um que ouvisse $)^{2}$

O tipo de energia envolvida nessas sentenças está atrelado ao conteúdo semântico do verbo. Podemos perceber que os verbos dar, transferir e contar exigem no cenário do evento um agente, um paciente e um beneficiário que ocupam, no português, as posições de, respectivamente, sujeito, objeto direto e objeto indireto. Verbos de comunicação e de transferência de propriedade envolvem o que Langacker (2002) chamou de transferência de energia abstrata.

Para retomarmos a análise de dados, é importante ressaltar que nos exemplos citados em 1 e 2 o participante 1 - agente, coincidia com o experienciador - aquele que sente ${ }^{3}$. Contudo, isso nem sempre ocorre. Por essa razão, podemos pensar em uma divisão entre as metáforas em que o agente coincide com o experienciador, as quais vamos chamar de metáforas com agente experienciador, e metáforas cujo agente pode ser externo, ou seja, nas quais o agente não correspondente ao experienciador. A seguir, apresentamos alguns exemplos de metáforas cujo agente é externo:

4 (a) A rotina é implacável, ela pode sufocar o amor http://blog.estadao.com.br/blog/palavra/title=quando_o amor acaba\&mo $\mathrm{re}=1 \& \mathrm{c}=1 \& \mathrm{tb}=1 \& \mathrm{pb}=1$

(b) Os terroristas querem matar o amor e a alegria http://www.geocities.com/cronistaarnaldo/alegria.htm

(c) Um telefonema proibido do Presidente venezuelano, Hugo Chávez, e a intransigência de Bogotá suspenderam as esperanças dos familiares dos reféns das Forças Armadas Revolucionárias da Colômbia (FARC). http://dn.sapo.pt/2007/11/23/internacional/uribe_afasta_chavez_negociac oes as f.html

\footnotetext{
${ }^{1}$ Texto original: "Though physical energy need not be involved, the subject in each case instigates the movement of the object, and can thus be construed as an abstract energy source". Tradução dos autores.

2 Tradução dos autores.

3 Langacker define experienciador como aquele que está envolvido em algum tipo de atividade mental.
} 
Em 4(a), observamos que a rotina assume o papel de participante 1 (agente) e, portanto, age em relação ao amor, que corresponde ao participante 2 (paciente). Logo, aquele que sente o amor não participa da ação. Temos, pois, uma metáfora cujo agente é uma causa externa. O mesmo ocorre em 4 (b) e (c). Isso nos leva a pensar que o tipo metáfora com agente experienciador (em que o experienciador coincide com o agente) pressupõe um certo controle da emoção pelo experienciador, ao passo que na metáfora com agente externo/causa externa parece haver por parte do experienciador um não-controle em relação ao sentimento.

No caso do agente, há uma ambiguidade em relação ao traço controle. Por ser agente, o participante mantém um domínio sobre a ação e transfere energia para o paciente (cf. LANGACKER, 2002, DOWTY, 1989; ACKERMAN; MOORE, 2001). Já por ser, ao mesmo tempo, um experienciador, a mesma entidade não detém o controle da sensação. Em relação a isso, Langacker (2002, p. 221) afirma que quando o experienciador aparece como sujeito ocorre uma interação assimétrica, pois não segue o fluxo de energia (AGENTE-->(INSTRUMENTO)--> PACIENTE) de uma ação prototípica: “o experenciador pode ser externamente induzido ou estar sob controle volitivo" 4 . Vejamos alguns exemplos em que o experienciador aparece na função de sujeito, no domínio literal, na situação de não-controle:

5 (a) Muitas pessoas viram o acidente.

(b) Joana lembrou da sua juventude.

Nesses casos o sujeito não compartilha das propriedades prototípicas do agente, isto é, tanto as muitas pessoas que viram o acidente, quanto Joana não tiveram propriamente um envolvimento volitivo no evento, não causaram o evento, não se movimentaram e nem transmitiram energia a outro participante.

Até agora, portanto, vimos que um enunciado metafórico pode ser equiparado a um enunciado não metafórico no que diz respeito ao cenário prototípico do evento. Esse cenário, baseado nos modelos cognitivos da ação, conta com dois participantes e, eventualmente, com algum instrumento. O participante 1 é aquele que exerce uma força sobre o participante 2, alterando o seu estado. Apontamos, no entanto, uma variável em relação ao participante 1 , que pode desempenhar dois papéis ao mesmo tempo: o de agente e o de experienciador. Evidenciamos, ainda, que o quadro cognitivo das metáforas que possuem o agente-experienciador é ambivalente em relação ao modo como representa a forma como lidamos com nossos sentimentos: tanto dominamos, quanto somos dominados por eles. Tanto controlamos os sentimentos, quanto somos controlados por eles.

\section{CONCEPTUALIZAÇÃO DA EMOÇÃO}

A emoção representada nas metáforas analisadas pode ou não corresponder aos traços atribuídos ao paciente. Nos modelos teatral e da bola de bilhar, o paciente prototípico é inanimado, receptor de energia e ocupa a coda na cadeia de transmissão de energia. Para metáforas com verbos como cortar, decepar, construir, destruir, desmontar etc, a noção

\footnotetext{
${ }^{4}$ Citação no original: "the experiencer may be externally induced or under volitional control”. Tradução dos autores.
} 
de entidade inanimada e receptora de energia, aplicada às emoções, se encaixa perfeitamente. Entretanto, nas metáforas com verbos como matar, afogar, sufocar, alimentar, afugentar, espantar etc, o sentimento é conceptualizado como um ser vivo, logo, o paciente não é inanimado. Consideremos os seguintes exemplos:

6 (a) Quero rever em meus pensamentos a sua imagem e destruir a saudade que na minha vida quer por fim.

http://www.poemas-de-amor.net/blogues/nikko/silencio_sem_eco

(b) O tempo se encarrega de construir a saudade

http://www.direito2.com.br/tjro/2007/mar/15/mensagem-ao-juiz-joseantonio-barreto

(c) Matei a esperança que eu mesma criei http://voxclamantisindeserto.arteblog.com.br/55211/RequiemConsagracao-Adoracao/

(d) A televisão não vai matar a paixão pelo livro http://www.revistaparadoxo.com/materia.php?ido=4935

Em 6 (a) e (b), observamos que o sentimento da saudade é conceptualizado como objeto, a partir do conteúdo semântico dos verbos destruir e construir. Já em 6 (c) e (d), o verbo matar sugere que os sentimentos de esperança e paixão são conceptualizados como ser vivo. Neste caso, as entidades não seriam pacientes prototípicos.

No entanto, no modelo da dinâmica de forças, as duas entidades em interação (antagonista e agonista) dispõem ambas de uma força intrínseca (TALMY, 2003). Ao contrário da percepção de que o paciente é uma entidade inerte, o agonista manifesta sempre uma tendência intrínseca, que se contrapõe à força exercida pelo antagonista, que por sua vez é o causador do evento. É do confronto entre as forças opostas do antagonista e do agonista que se origina a mudança (ou perpetuação) de um estado de coisas. Essa estrutura conceptual da ação causal faz com que tanto um ser inanimado, quanto um ser animado imponham naturalmente uma força oposta àquela exercida pelo antagonista. Se alguém empurra uma pedra, por exemplo, o antagonista é o ser humano, mas ele encontra a resistência da pedra (o agonista), a qual se manifesta através de sua tendência ao repouso (efeito do peso e da gravidade).

As metáforas analisadas preservam essa estrutura do modelo da dinâmica de forças, independente da ontologia da emoção metaforizada. Assim, em 6(a), a saudade é conceptualizada como um objeto cuja simples existência impõe uma força contrária ao desejo do antagonista, que corresponde ao sujeito experienciador.

As metáforas analisadas combinam uma cena cognitiva teatral com uma cena cognitiva de força. Na cena teatral, uma entidade (o agente-experienciador) age voluntariamente sobre a emoção que ele sente. A emoção reificada é o objeto da cena verbal. Vemos o experienciador e a emoção agirem como personagens, um ativo e outro passivo. Na cena de dinâmica de forças, que se amalgama com a cena teatral, a emoção não apenas adquire existência própria, como exerce ela também uma força, se opondo ao antagonista (o agente-experienciador). 
Essa percepção de relação de forças entre experienciador e emoção às vezes é marcada pela escolha de verbos do campo semântico da luta e do confronto. O combate aqui se dá entre duas entidades internas ao sujeito: a emoção ganha vida própria e exerce sua força sobre o experienciador.

7 (a) Resta-nos então ter força para enfrentar o amor / dor. http://oqueamor.blogs.sapo.pt/arquivo/154406.html

(b) Segundo ele, é preciso combater a paixão pelo mero exercício do poder e a servilidade diante dos poderosos. http://www.usp.br/agen/bols/extras/2004/extra069.htm

(c) Hamas ensina crianças de Gaza a lutar contra o medo http://noticias.uol.com.br/ultnot/afp/2006/07/10/ult34u158096.jhtm

É interessante observar que nos casos exemplificados em (7), as metáforas parecem resolver a ambivalência de controle e não-controle, por parte do experienciador, apresentada na seção anterior. Se há um conflito de forças, há uma clara indicação de não-controle do sentimento. Ou então, pelo menos, o controle que se obtém de uma emoção é percebido como o resultado de um conflito.

Podemos verificar, contudo, alguns exemplos em que o experienciador e a emoção não apresentam uma relação antagônica de forças:

8 (a) 30 dicas para alimentar o amor. http://itodas.uol.com.br/portal/amor_e sexo/romantismo/3 dicas que a limentam o amor/materia.itd.aspx?cod $=944 \&$ canal $=604$

(b) Queria acima de tudo, manter o contacto com a mãe e alimentar a saudade.

http://obloguedocastelo.blogs.sapo.pt/199391.html?mode=reply

Nesses exemplos o agente-experienciador tem controle, ao menos momentâneo, da ação. Poderíamos pensar, nesses casos, em um agonista (a emoção) potencialmente conflituoso que estabele, no entanto, uma relação de cooperação com o antagonista (o experienciador). Nesse caso, experienciador e emoção caminham num mesmo sentido. De fato, Talmy (2003) já previa esses casos em que antagonista e agonista colaboram, ou seja, exercem suas forças numa mesma direção.

Consideremos agora alguns exemplos que apareceram em nossos dados, em que percebemos uma interação antagônica entre os dois participantes da cena das emoções:

9 (a) eu matei o amor, e ele matou o ódio. http://nalixeira.blogspot.com/2007/06/amor-e-dio.html

(b) Se foi o calor, cresceu o rancor e afogou a paixão. http://www.lyricsondemand.com/p/pregadorluolyrics/maisumachancelyri cs.html

Nesse caso, o antagonismo se dá não entre o experienciador e a emoção que ele sente, mas entre dois sentimentos distintos. Na cena teatral, sobem ao palco duas emoções, e 
elas entram em conflito. $\mathrm{O}$ experienciador fica apagado e parece ser totalmente passivo em relação ao que ele sente.

\section{CONCLUSÃO}

Com base na análise realizada, podemos identificar uma série de características comuns às metáforas estudadas. Essas características derivam do fato de que os enunciados sobre emoções foram codificados por meio de estruturas verbais transitivas, que evocam modelos cognitivos de ação. Assim, os enunciados metafóricos herdam estruturas conceptuais associadas a enunciados literais (cf. MOURA, 2007; 2008). Três modelos cognitivos de ação serviram de base para a análise dos dados: o modelo teatral, o modelo da bola de bilhar e o modelo da dinâmica de forças. Com base nesses três modelos, podem ser identificadas as seguintes características das metáforas analisadas:

1) As emoções são reificadas, como entidades externas ao sujeito.

2) Os participantes da cena verbal (o ser humano e a emoção) ocupam lugares distintos no espaço ideacional.

3) Os participantes da cena verbal têm força própria.

4) Há transferência de energia entre os participantes da cena.

5) O agente (o ser humano) é um participante que age voluntariamente, como fonte de energia.

6) O paciente (a emoção) é um participante que absorve a energia transmitida pelo agente, sofrendo uma mudança de estado.

7) Os participantes podem estar em conflito, como forças antagônicas, ou podem colaborar numa mesma direção.

8) A relação entre o antagonista (o ser humano) e o agonista (a emoção) é ambivalente em relação ao controle: como agente, o ser humano tem controle da emoção; como experienciador, não tem controle do que ele sente.

A essas características comuns aos enunciados metafóricos estudados, vem se sobrepor a especificidade da metáfora ontológica, associada ao verbo que é o veículo da metáfora. Assim, dependendo do verbo escolhido, a emoção pode ser conceptualizada como ser consciente, objeto, ser vivo, artefato ou doença. Portanto, as metáforas estudadas herdam sua estrutura conceptual tanto de modelos mais gerais, associados a certas estruturas gramaticais (como as sentenças transitivas), quanto do conteúdo conceptual associado a itens lexicais específicos, como, por exemplo, os verbos afugentar, destruir, sufocar, desmontar e extirpar. Em alguns casos, o modelo cognitivo mais geral (como o modelo da dinâmica de força) é reforçado pelo conteúdo lexical do verbo, como ocorre na sentença Resta-nos então ter força para enfrentar o amor / dor. Neste caso, o antagonismo entre o experienciador e a emoção deriva tanto da dinâmica de forças (antagonista e agonista têm forças contrárias), quanto do conteúdo conceptual associado ao verbo enfrentar. 


\section{REFERÊNCIAS BIBLIOGRÁFICAS}

ACKERMAN, F. \& MOORE, J. Proto-properties and grammatical encoding: a correspondence theory of argument selection. Chicago: University of Chicago Press, 2001. 197p.

DOWTY, D. On the semantic content of the notion 'thematic role': In: Chierchia, G., Partee, B. H. and Turner, R. (editors), Properties, Types, and Meaning 2. Kluwer: Dordrecht, 1989.

DOWTY, D. Thematic Roles and Argument Selection. Language 67: 547-619. 1991.

LAKOFF, G. \& JOHNSON, M. Metaphors we live by. Chicago: Chicago University Press, 1980. 242p.

LANGACKER, Ronald W. Concept, image and symbol: the cognitive basis of grammar. 2. ed. Berlim; New York: Mouton de Gruyter, 2002. 395p.

MOURA, H. Metáfora: das palavras aos conceitos. Letras de hoje 40- 139, 20-45. 2005. . Relações paradigmáticas e sintagmáticas na interpretação de metáforas. Linguagem em (Dis) curso 7-3, 417-452. 2007.

. Desfazendo dicotomias em torno da metáfora: Revista de Estudos da Linguagem 16:2 (2008).

PINKER, S. The stuff of thought. Language as a window into human nature. New York:Viking, 2007. 499p.

REDDY, M. The conduit metaphor: a case of frame conflict in our language about language. In A. Ortony (Ed.), Metaphor and Thought. New York:Cambridge University Press, 1993.

TALMY, Leonard. Toward a cognitive semantics 2. Cambridge (Mass.):The Mit Press, 2003. 495p. 